\title{
A Roadmap for successful IoT implementation: empirical evidence from the energy industry
}

\author{
Shahid Hafeez, University of Vaasa, shahid.hafeez48@gmail.com \\ Oskar Juszczyk, University of Vaasa, oskar.juszczyk@uwasa.fi \\ Josu Takala, University of Vaasa, josu.takala@uwasa.fi
}

\begin{abstract}
The Internet of Things has become a spotlight in contemporary literature in the domain of industry 4.0 and emerging technologies. Majority of research studies focuses on technicalities and theoretical implications of implementing IoT in the energy sector. However, in practice, organisations face a combination of technical and non-technical challenges. There is a clear need for the studies to empirically evaluate IoT use cases, challenges, and a roadmap for successfully implementing emerging technologies. To fulfil the research gap and provide insights for practitioners, we conducted seven semi-structured interviews with professionals working in Finland's energy sector. Based on results retrieved through content analysis of transcribed interviews, we developed a roadmap with managerial implications for successfully implementing IoT and other emerging technologies. Furthermore, study results present practical insights on IoT applications, benefits, and major IoT utilisation challenges in the Finnish energy sector industrial ecosystem. In the end, conclusion and future research directions are discussed.
\end{abstract}

Keywords: Internet of Things, industry 4.0, innovation management, product development, manufacturing, implementation roadmap

\section{Introduction}

\section{Background of the study}

A plethora of studies (Georgakopoulos et al., 2016; Lasi et al., 2014; Lin et al., 2016; Lu, 2017; Pfeiffer, 2016; Roblek et al., 2016) on industry 4.0 indicates a steep transition is underway towards the fourth industrial revolution during the last decade. The concept of industry 4.0 is mainly referred to digitalisation and automation of different industrial activities with the help of disruptive technologies such as the Internet of Things (IoT), big data, Artificial intelligence (AI), robotics, autonomous vehicles, 3D printing, nanotechnology, biotechnology, material sciences, energy storage \& production and quantum computing (Schwab, 2017). Like other disruptive technologies, the IoT technologies seek to accelerate the pace of transition by providing advanced centralised automation solutions for various industrial applications ( $\mathrm{Lu}$, 2017). Adoption and utilisation of IoT are expanding across the industries due to the vast breath IoT ecosystem, including intelligent and embedded system shipments, connectivity services, platforms, applications, analytics, security, infrastructure, and other professional services. These features gives leverage to IoT over other competing technologies, ultimately, a remarkable growth has been observed in IoT utilisation in the industry and still growing exponentially. Khan et al. (2020) suggests that the market share of IoT is expected to reach 14.2 trillion dollars by the end of 2023, whereas the number of IoT devices 


\section{Issues in Information Systems}

Volume 22, Issue 1, pp. 92-113, 2021

can reach 70 billion devices in 2025. Similarly, Lund et al. (2014) reports a 20\% compound annual growth rate for the IoT market; thus, IoT is deemed imperative technology in industry 4.0.

However, with industrial systems' advancements, industrial activities' energy consumption is also posed to go up (Arshad et al., 2017). Those advancements in technology and industrialisation have led to higher energy demand worldwide by $2.3 \%$ in 2018 (IEA, 2019). Tao et al. (2016) reports about $37 \%$ of available global energy are consumed by the industrial sectors. And to date, a larger portion of current energy demand is met using fossil fuels such as oil $31.5 \%$ and coal $26.9 \%$ (IEA, 2020). Consequently, with the massive increase in energy demand, energy sector $\mathrm{Co} 2$ emissions simultaneously also reached a new peak. Recent IPCC report clearly indicates how greenhouse gases and $\mathrm{Co} 2$ emissions have catastrophic effects on climate systems (IPCC., 2019). In Finland's case, the country's energy mix still largely (43\%) depends on fossil fuels-based energy such as coal, natural gas and oil (Shakeel et al., 2017; IEA, 2019), the urgency to develop an efficient energy management system and renewable technologies even goes high. The country also imports a substantial part of its energy needs, thus achieving efficiency throughout the energy sector's industrial ecosystem is crucial for Finland. Similarly, data illustrates in 2019, Finland's industrial energy consumption remained $45 \%$, transportation accounts for $17 \%$, space heating $26 \%$ and other $12 \%$ (Final Consumption of Energy - Motiva, n.d.). Moreover, the EU 2030 target for Finland compels the country to emphasise the development of Renewable Energy Sources (RES) and increase the share of RES to 51\% while limiting the energy consumption to 290 terawatt-hour through an efficient energy management system (Finland's Integrated Energy and Climate Plan, 2019).

The IoT paradigm offers novel industrial solutions by connecting products, assets, and production plants through embedded sensors and actuators, ensuring real-time data sharing and process monitoring (Nord et al., 2019). Studies suggest that IoT technologies can revolutionise the entire industrial sectors. Its offering includes but not limited to the development of RES, smart grids, energy transmission, distribution, and consumption (Hossein Motlagh et al., 2020; Tan et al., 2017) smart manufacturing, smart factory (Hozdić, n.d.), product life cycle management (Cai et al., 2014), supply chain \& logistics (Abdel-Basset et al., 2018), asset management (Brous et al., 2019) safety in high-risk environments (Gnoni et al., 2020; Thibaud et al., 2018) to name a few. However, as a common phenomenon attached to emerging technologies, organisations face various kind of challenges in implementation and utilisation process of IoT. These challenges ranges from technical challenges to a high level of resistance to change from different stakeholders of the organisation. Implementation of such technologies requires the organisation to understand challenges, use cases, and a framework to overcome those barriers. Reviewing pertinent literature on the IoT domain shows, studies are scant which provides roadmap with managerial implications for successful IoT implementations. Furthermore, an empirical evaluation is required to enhance understanding of major challenges, use cases and primary benefits related to IoT implementation and utilisation in practical scenario. Therefore, we tried to fulfil the research gap by identifying priority application areas, leading benefits, major barriers, and a roadmap for practitioners to implement IoT in their organisation successfully. Moreover, the study also evaluates practitioners' views on the utilisation of Artificial Intelligence (AI) and Blockchain (BC) technologies in the Finnish energy sector's industrial ecosystem.

\section{Literature review}

\section{Internet of Things}

Although Kevin Ashton introduced IoT technologies in 1998, yet the technologies are in the state of infancy, therefore, there is a lack of consensus on any universal definition of the technologies in academia 


\section{Issues in Information Systems}

Volume 22, Issue 1, pp. 92-113, 2021

(Čolaković \& Hadžialić, 2018; Nord et al., 2019; Wortmann \& Flüchter, 2015). Various definitions are presented based on the context of utilisation and vision of the researchers (Čolaković \& Hadžialić, 2018; Gigli \& Koo, 2011; Lee \& Lee, 2015; Lund et al., 2014; Tao et al., 2016). However, most researchers have consensus on the operational mechanism, utilisation framework, and objectives of the IoT. In a broader perspective, these technologies utilise the Internet, communication technologies, standards to connect remotely with physical objects which have embedded sensors and actuators to sense and act in different situations (Al-Fuqaha et al., 2015; Čolaković \& Hadžialić, 2018; Haseeb et al., 2019; Hossein Motlagh et al., 2020; Zouinkhi et al., 2020). Similar to the definition, various architectural frameworks have been presented, for instance (Nord et al., 2019) shows three layers of IoT structure; whereas (Hossein Motlagh et al., 2020; Mrabet et al., 2020) discuss five main layers, i.e., physical sensing, networking, transport, application, and data cloud services layer.

The physical sensing layer includes different sensors and actuators to sense and respond to the situation (Hossein Motlagh et al., 2020; Mrabet et al., 2020) networking layer consist of short- and long-range networking and communication technologies such as Lora, LTE, NFC, Bluetooth, WIFI, Zigbee. Different internet protocols are used in the transport layer such as TCP/IP, UDP/IP, while other application protocols are utilised based on IoT system requirements in the application layer. Finally, data cloud services include different cloud-based services and data analytics available to IoT systems such as Google IoT, Cisco, and Bosh (Mrabet et al., 2020). This multilayer mechanism gives leverage to IoT over traditional competing wireless communication technologies. The efficient utilisation of sensors \& actuators, connectivity, and IoT data sharing capabilities can provide meaningful information in the energy sector.

Meanwhile, these technologies also provide novel solutions in energy transmission, distribution, smart grid, microgrids, and to optimise final energy consumption patterns (Hossain et al., 2016; Hossein Motlagh et al., 2020). A large share of the global energy supply is consumed by industrial and logistics systems (Dyer et al., 2008); therefore, it is imperative to monitor, control, and optimise final energy consumption in industrial systems. Industrial systems consume energy in various ways, such as manufacturing, transportation and logistics, heating and cooling systems, and energy consumed by-products for end customers. In this perspective, IoT enhances energy efficiency; instead, it may lead to new business models, new product development, optimisation of supply chain and logistics processes, and manufacturing quality improvement.

\section{Previous research on IoT applications and challenges in energy sector Applications}

The importance and energy presence can be traced back to the early ages of the human race; however, modern energy and power concepts become spotlight with advancements in industrial and mechanical systems. In contemporary times, energy has deemed a backbone of all industrial activities, the ever-growing demand has shaped a sophisticated supply chain in the energy sector with three distinct phases, i.e., energy supply, transformation, and consumption (Bhattacharyya, 2011). Numerous research studies (Bandyopadhyay \& Sen, 2011; Chen et al., 2014; Maple, 2017; Shaikh et al., 2017) demonstrate potential IoT applications in industrial systems. A study by Hossein Motlagh et al. (2020) presents theoretical potential of utilizing IoT in energy production, distribution, and consumption. Ramamurthy \& Jain, ( 2017) discuss how IoT can increase real time efficiency and increase predictive maintenance in energy systems. Similarly, in their research Al-Ali, (2016) debate RES technologies are better alternative to traditional energy sources, and IoT based solution can ignite the development of RES as IoT provides a balance in the generation of energy, optimising energy usage through machine learning algorithms and enhance energy efficiency (Ramamurthy \& Jain, 2017). Moreover, study by Al-Turjman \& Abujubbeh, (2019) evaluates role of IoT in micro grids and Hossein Motlagh et al. (2020) studied IoT in context of smart grids. 


\section{Issues in Information Systems}

Volume 22, Issue 1, pp. 92-113, 2021

Besides applying IoT in energy generation, transmission and consumption, the industrial ecosystem is contemplated by other industrial applications. Studies shows IoT have the potential to innovate manufacturing process (Mourtzis et al., 2016; Wan et al., 2018), transportation \& logistics (Hopkins \& Hawking, 2018; Ejaz et al., 2017), commercial products (Porter \& Heppelmann, 2014), domestic buildings (Khanda et al., 2017), lighting, heating, and cooling (Hossein Motlagh et al., 2020), asset management, predictive maintenance (Teoh et al., 2021), product development (Cai et al., 2014, 2014; Golovatchev et al., 2016), and customer experience (Hoyer et al., 2020; Nguyen \& Simkin, 2017).

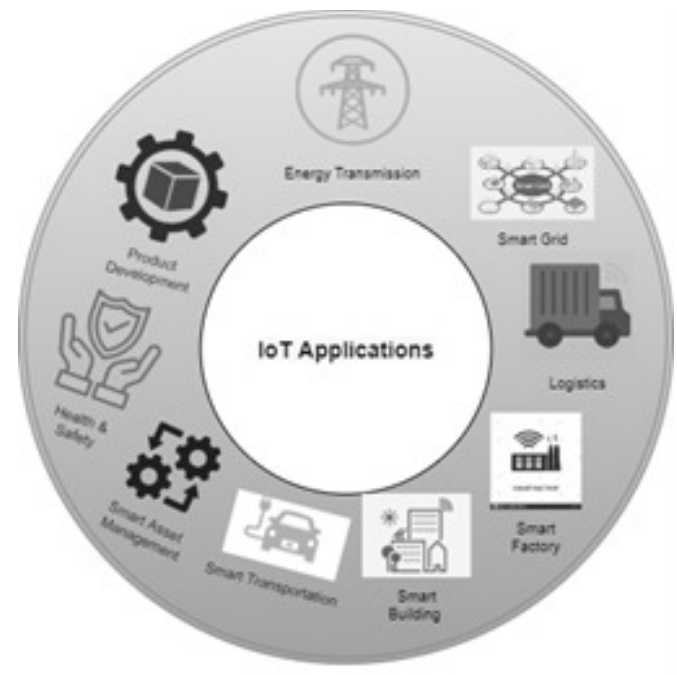

Figure 1. Examples of IoT applications

\section{Key challenges of the IoT implementation}

Many studies (Farhan et al., 2017; Hsu \& Lin, 2016; Kumar \& Mallick, 2018; Lennvall et al., 2017; Younan et al., 2020) are conducted to evaluate challenges in implementing IoT. The majority of studies focus only on technical challenges (Alabdulsalam et al., 2018; Das, 2015; Ghorbani \& Ahmadzadegan, 2017; Hameed et al., 2019; Jing et al., 2014; Kecskemeti et al., 2017; Sood et al., 2016; Virat et al., 2018; Weber, 2010). Only a few researchers studied non-technical challenges such as return on investment and social perspective on IoT implementation (Kumar \& Mallick, 2018; Ouaddah et al., 2017).

Among technical challenges, Younan et al., (2020) discuss integration among the technologies, scalability, network, and communication are the main challenges. Kumar \& Mallick (2018) studied security, privacy, interoperability, standardisation, legal regulatory, and economic / investment issues related to IoT implementation. Similarly, AlEnezi et al. (2018), reported security, privacy, and investment are the main issues, whereas Farhan et al., (2017) examine challenges related to scalability, energy requirement, security, and fault tolerance of IoT. Furthermore, a study by (Lennvall et al., 2017) found organisation can face many challenges i.e., installing \& retrofitting, security, reliability, availability, scalability, interoperability, sustainable business model. Most studies suggest IoT security and privacy is biggest concern, (Nord et al., 2019) discuss IoT mainly operates through wireless technologies and share data through different IPs and networking technologies prone to cyber-attacks or data breaches. Following privacy and security issues, trust is a significant concern in IoT implementation. In the perspective of information security, trust can be divided into three dimensions: trust competence, benevolence, and integrity (Paliszkiewicz, 2019). Trust 


\section{Issues in Information Systems}

Volume 22, Issue 1, pp. 92-113, 2021

plays a vital role in predicting employee's compliance towards organisation information security (Koohang et al., 2020); therefore, trust cannot be neglected in information security and privacy companies.

Compared to technical challenges, non-technical challenges have got little attention in the literature. Only a handful of studies focuses on non-technical challenges such as investments, return on investment (ROI), financial feasibility (AlEnezi et al., 2018; Nord et al., 2019), social and organisation level barriers (Ouaddah et al., 2017) in IoT implementation. For organisations, ROI is a critical factor in implementing new technologies as they need stable returns on their investments (Lim et al., 2013; Ouaddah et al., 2017). Sometimes it is hard for organisations to justify huge investments in new technologies unless they expect clear benefits in implementing new technologies. Other than financial factors, (Nord et al., 2019; Ouaddah et al., 2017) report social constraints, cooperation among the departments and organisational culture also hinder IoT growth.

Table 1 summarise key studies on IoT in different contexts.

Table 1. Key studies on IoT

\begin{tabular}{|l|l|l|}
\hline Authors & $\begin{array}{l}\text { Paper } \\
\text { classification }\end{array}$ & Main contribution \\
\hline $\begin{array}{l}\text { Ingemarsdotter et al. } \\
(2020)\end{array}$ & Case study & $\begin{array}{l}\text { Opportunities and challenges in IoT implementation in } \\
\text { circular business model. }\end{array}$ \\
\hline Stoyanova et al. (2020) & Survey & $\begin{array}{l}\text { IoT technical challenges, cloud data communication } \\
\text { framework. }\end{array}$ \\
\hline Nižetić et al. (2020) & Survey research & $\begin{array}{l}\text { IoT theoretical opportunities; smart city, industrial IoT, } \\
\text { connected health, smart homes, wearables, others. } \\
\text { Technical challenges and framework. }\end{array}$ \\
\hline Paiola \& Gebauer. (2020) & $\begin{array}{l}\text { Qualitative survey } \\
\text { research }\end{array}$ & $\begin{array}{l}\text { Firms' strategic transitions in digitalization servitization } \\
\text { through IoT technologies in B2B manufacturing firms. }\end{array}$ \\
\hline Younan et al. (2020) & Literature review & $\begin{array}{l}\text { Evaluation of challenges: Integration among technologies, } \\
\text { scalability, network, communication, data analytics. }\end{array}$ \\
\hline Nord et al. (2019) & Literature review & $\begin{array}{l}\text { Theoretical framework and evaluated challenges: } \\
\text { Security, trust, networking, investment, cross department } \\
\text { cooperation, skilled people, network challenges, too few } \\
\text { best practices. }\end{array}$ \\
\hline $\begin{array}{l}\text { Čolaković \& Hadžialić. } \\
\text { (2018) }\end{array}$ & Review paper & $\begin{array}{l}\text { Enabling technologies. Technical challenges; security, } \\
\text { privacy, trust, standardization, scalability, authentication, } \\
\text { Access control. }\end{array}$ \\
\hline (Pflaum \& Golzer, 2018) & Literature review & $\begin{array}{l}\text { IoT and big data role in digitalization of business } \\
\text { organizations. }\end{array}$ \\
\hline (Hsu \& Lin, 2018) & $\begin{array}{l}\text { Quantitative } \\
\text { china. } \\
\text { survey }\end{array}$ & Survey research \\
\hline Kumar \& Mallick (2018) \\
$\begin{array}{l}\text { Evaluated challenges: Security, privacy, interoperability, } \\
\text { standardization, legal regulatory, economic / investment. }\end{array}$ \\
\hline
\end{tabular}




\section{Methodology}

Current study aims to empirically identify key application areas, benefits, major barriers, and provide a roadmap to implement and utilise IoT in the energy sector successfully, the current study is based on the qualitative research design. IoT technologies are in their phase of infancy and research studies in this domain started conceptualizing IoT related theoretical frameworks. We believe getting practitioners view through detailed discussion will help us to get an in-depth insight on different concepts and allow us to tap untapped aspects of IoT technologies in practical cases. Pathak et al. (2013) reports qualitative methods are best suited when research aims to comprehend people's belief, experiences, or attitudes towards certain concepts, phenomena, and topics. Earlier studies (Kummitha \& Crutzen, 2019; Schmitt et al., 2019) have also proven significance of utilizing semi structured interviews based qualitative research design to evident IoT role in smart city and smart contracts in organizational settings. Thus, we conducted in-depth online semi-structured interviews with professionals working in the Finnish energy sector industrial ecosystem. Gill et al. (2008) emphasises that semi-structured interviews are best suited as it facilitates the researcher to set key questions before the interview and ask follow-up questions based on the ongoing discussion. IoT as an emerging technologies demand researcher to dive deep to tap untapped theoretical concepts and actual implementations. We utilised a semi-structured interviews method to serve the purpose of the study by asking key and follow-up questions.

Purposive sampling technique was used Yin (1994) since we screened companies reports and discussed with industry experts to potentially identify companies utilizing IoT and experts working in IoT domain in Finnish energy sector. We found a total 30 experts from 25 companies were invited for interviews and 7 participants from 7 different companies agreed for online interviews. Interviews were conducted during October 2020 to December 2020. External validity is ensured as the participants organisations include but not limited to the global leader in marine power and energy business, power and mechanical solutions for marine engines, industrial equipment suppliers for the energy sector, leading digital business services providers for energy solutions, etc. Furthermore, three point criteria was followed to select the participants 1) professionals with at least three years of experience in the same organisation operating in the Finnish energy sector, 2) they have adequate knowledge of technicalities and use cases of IoT in their organisation as one of the research objective is to evaluate technical challenges faced by organizations in IoT implementation and utilizations, 3) also their role in the organisation is among middle level or top-level management so that they can present a strategic perspective on IoT implementation in the particular organisation. Moreover, they were well aware of the implementation process and strategical aspects of emerging technologies implementation in their organisations. Background information, position, the experience of the participants, and their organisation products can be found in appendix A.

\section{Data analysis}

Data was collected through an online survey and semi-structured interviews. Interviews were conducted online through Zoom video interviews. We recorded interviews with the exclusive consent of participants, and later on, interviews were transcribed. Average time per interview remained around 30 minutes, and to minimize the researcher biasness, collected data was transcribed, coded, and analysed using systematic content analysis. To validate the results, data triangulation was carried out through careful review of company reports and blogs. Wilson et al. (2015) suggest blogs as tools for qualitative research have great potential to identify and contemplate qualitative results. As a results of content analysis, we found four broader themes a) major applications and utilities of IoT, b) Major challenges related to IoT implementation and utilisation, c) main benefits organisation achieved through IoT implementation, and lastly d) development of a roadmap for successful implementation of emerging technologies, i.e., IoT, AI, and BC technologies. 


\section{Results of the study}

\section{Empirical evidence on major application and utilities of IoT in the energy sector}

Empirical results show information technology, manufacturing, and smart grid are the top three IoT applications in the energy sector of Finland. Study results confirms there is match between IoT theoretical opportunities (Nord et al., 2019; Hopkins \& Hawking, 2018; Ejaz et al., 2017; Teoh et al., 2021; Cai et al., 2014; Golovatchev et al., 2016) and real time industry implementations. For example, IoT in smart manufacturing enables organisations to monitor machines inside the manufacturing process, connect equipment with embedded sensors that monitor, and share real-time data with cloud services on the performance of the equipment. Collected data is utilised in real-time condition monitoring, performance review, and increased production quality.

Likewise, it was revealed that similar to IoT theoretical opportunities in energy sector (Hossain et al., 2016; Hossein Motlagh et al., 2020), these technologies in practice offer horizontal solutions in various activities of the energy sector; in power quality monitoring, smart grid to stabilise the grid frequency, power consumption pattern analysis, power plants optimisation, energy storage solutions and development of RES such as solar and wind power energies. Upon asking about IT and IoT, interviewees expressed their experience as IT is a major area of application with IoT, and it is a core area to integrate with IoT. Similarly, the result shown product development, asset management, customer experience, and safety are major IoT utilities. IoT contributes to the product development of various products. It is evident from results and literature studies such as (Brous et al., 2019; Smidt et al., 2018) IoT has a primary role in asset management. The importance of IoT even critical in the context of marine technology where it is essential to monitor engine energy consumption, performance, equipment safety, and early error detection is required. Nevertheless, asset management and predictive maintenance in large production plants, factories, and facilities are equally essential, and participants' discussion shows IoT has a high level of utilisation in asset management. Participants views on application and utilisations of IoT can be found in Appendix B.

\section{Empirical evidence on major challenges in IoT implementations}

We found two main sub-themes on major barriers in IoT implementation and utilisation; 1) technical challenges, 2) non-technical challenges. Results on technical challenges are well aligned with literature studies (Čolaković \& Hadžialić. 2018; Younan et al., 2020; Kumar \& Mallick. 2018) major challenges include privacy, network issues, integration among the technologies, authentication, access control, and mobile security. The most prominent technical barrier organisations face is privacy and integration among the technologies. IoT technologies integrate different platforms, and all the data is shared through wireless communication protocols using various communication technologies. Data shared over wireless devices and servers can potentially be accessed by unauthorised parties which could be fatal for organisations. Since data contains important information about certain areas of the organisation; therefore, most of the organisations are concerned about privacy, which potentially hinders the higher-level adoption of IoT in the industry. Similarly, it was also found replacing existing technologies at a large scale most of the time is not economically and technically feasible for organisations. IoT needs to be integrated with existing technologies in this context, and many participants found it is much challenging for practitioners to integrate IoT with existing technologies.

However, results on non-technical challenges presents challenges less discussed in literature, yet of high importance. Return on investment among non-technical challenges is biggest challenge, followed by too 


\section{Issues in Information Systems}

Volume 22, Issue 1, pp. 92-113, 2021

few best practices, cooperation among departments, lack of strategic approach, employee's behaviour, and resistance to change. All participants believe organisations are mainly concerned with ROI, as these technologies often require huge initial investments and higher replacement costs. Also, there is a lack of vision to streamline financial gains by implementing new technologies, which hinders extensive scale utilisation and implementation of IoT in the industry. However, participants emphasised that most of the projects related to IoT implementation are in their initial phases. They perceive financial benefits in the future, enhancing industry leaders' understanding of IoT economic opportunities. Results also suggest that organisational culture, employees' behaviour, management commitment, and acceptance to change is equally vital in the success of emerging technologies, especially, IoT and AI implementation. Analysis of data highlights an organisational culture that supports change management, employees' training and attitude, leadership commitment to innovate plays deciding role in the success or failure of ICT-related projects. Sample quotations on participants discussion on major challenges is listed in Appendix C.

\section{Opportunities offered by IoT}

The primary purpose of implementing any technology is to grab on opportunities they offer. IoT are emerging technologies and there is limited understanding of opportunities IoT offers to the industry in different application areas. Therefore, we tried to clearly define what have already achieved benefits of IoT practical utilisation in the industrial ecosystem of Finland's energy sector. Results revealed that IoT is still in its early stages of utilisation, yet most participants indicated they had realised clear benefits. Utilising IoT has been beneficial to sample organisation in terms of increased energy efficiency, enhanced user experience, financial savings by cutting the cost, improved product quality, supply chain efficiency, new value streams, and health \& safety. Some participants explained their project on IoT has just started, and they are yet to realise the benefits. However, they perceive IoT will bring a higher level of efficiency in their manufacturing process, and data collected through embedded sensors can open up new revenue streams for them. The diagram shows the major benefits of IoT utilisation. A summary of participants discussion on IoT benefits is given in Appendix C.

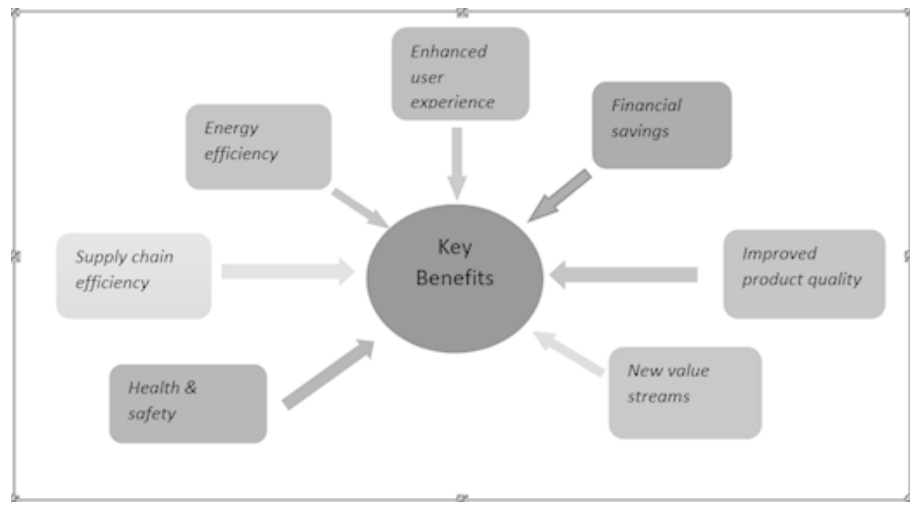

Figure 2. Key benefits of IoT implementation

\section{Roadmap for successful implementation of IoT and other emerging technologies}

The organisations met with certain challenges in implementing and utilising emerging technologies such as IoT, AI, and BC. Those challenges expose organisations to different kinds of threats, which potentially cause the total or partial failure of the new technologies related projects. Failure of the technology-related project can eventually result in a loss of substantial financial investments, unable to grab opportunities offers by new technologies, and allowing competitors to capture market share. To avoid such circumstances, 


\section{Issues in Information Systems}

Volume 22, Issue 1, pp. 92-113, 2021

based on the interviews, we developed a roadmap for the successful implementation of emerging technologies, i.e., IoT, AI, and BC. The essence of the roadmap stands on a combination of strategical and operational level initiatives.

According to participants, stakeholders' engagement is a critical factor in emerging technologies implementation. It is indispensable to take all stakeholders on board throughout the implementation process. They suggested communicating the need and value of implementing new technologies to employees and all tiers of management. Employees and management commitment play a decisive role in the success or failure of technology. It is often observed that employees resist new technologies implementation as they might feel threatened by new technologies and change. Therefore, it is crucial to engage and onboard all key stakeholders. Another critical factor is management commitment and role in technology implementation. Leadership commitment to emerging technologies performance is deemed as a cornerstone as they have decision making authority. Participants explained a committed leadership could motivate and synchronise employees to achieve objectives more effectively. Employees' and management's synchronised efforts can have an exponential effect on the success of the technology-related project. A highly committed management enhances project teams' productivity which eventually leads to impressive results.

Defining clear and measurable objectives plays important role in success of the technology related projects. It was found out that most of the technology-related projects fail because of ambiguous goals. The organisation must know what they want to achieve by implementing new technologies and what kind of business value they will achieve through emerging technologies. Other key strategical initiatives include inventing business cases and cooperation among the industry. To successfully implement emerging technologies, an interviewee recommended to develop business cases, be specific and clearly define areas of improvement. Defining a business case offers twofold opportunities; first it helps project team to be more focused and track progress, while it also helps organizations to tackle issue of ROI. For example, defining a business case helps organizations to find out do they require new business streams, energy efficiency, process efficiency, new product lines, adding value to existing products, etc.? on other hand it also helps to tackle ROI since project aims to generate new revenue streams or increase existing process efficiency which can potentially increase savings and give financial benefits. To tackle ROI issue, organizations can also use low hanging fruit technique and try to start utilizing new technologies from basic to advance level. Emerging technologies are in their infancy phase; the industry lacks standardisation of frameworks and structures and frameworks are continuously evolving; therefore, it was highly recommended by interviewees to boost cooperation among the organisations to enhance the common understanding in the technologies.

As discussed, a combination of operational and strategical level initiatives is required to implement these technologies successfully. Interviewees indicate that mapping the user journey, employee training, and intra-organization communication increases technology-related projects' success. Employee training and effective communication across the organisation are crucial, as training helps employees gain technical skills required to deal with new technologies and can also be used as an opportunity to share the need and value of technology under consideration. This way, it can increase employee's motivation and decrease their resistance to change. 


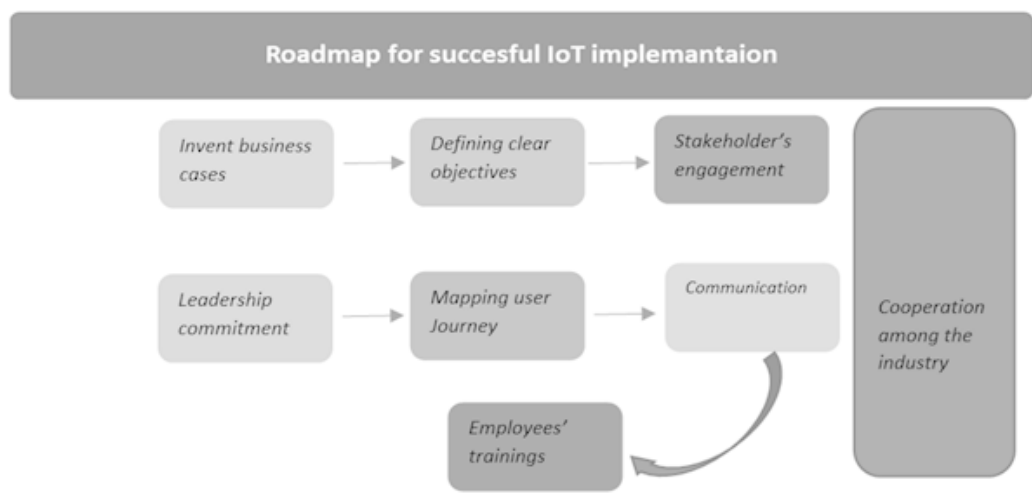

Figure 3.Developed roadmap for a successful IoT implementation

\section{Discussion and conclusion}

We tried to systematically evaluate key application areas, benefits, and major challenges and develop a roadmap with practical insights for a successful implementation of IoT. Furthermore, a roadmap for successful IoT implementation has generalizability to other emerging technologies such as AI, BC, and extended reality (XR) across the different industrial sectors. Retrieved results indicate that our findings on significant applications and critical technical challenges on IoT implementation and utilisation are well aligned with theoretical opportunities. However, we also identified some non-technical challenges which are less addressed in the literature.

We found out IoT has application in all major areas of the organisations operating in the industrial ecosystem of Finland's energy sector. Lead application of IoT is information technology as data and information play a crucial role in the contemporary business environment. Therefore, most sample organisations focus heavily on efficient information technology systems supported by emerging technologies, i.e., IoT. Integration of IoT in their IT system has enabled organisations to collect vast amounts of data for various purposes such as data-driven business models, decision-making, process improvement, and increasing health and safety. Empirical evidence also indicates IoT has a more prominent role in product development, marine engine efficiency, and customer experience. IoT has offered various solutions to the product owners through embedded sensors and the capability to share real-time data. Product owners can monitor product consumption patterns and data on the performance of product mechanical and electric components. Collected data helps product owners understand customers' needs, potentially opening new product lines or opportunities for continuous improvement in existing products.

Similarly, IoT applications in marine powers opened new avenues for the industry to increase energy efficiency, critical error predictions, and predictive maintenance. IoT also has a crucial role in asset management, as well as the utilisation of different IoT technologies such as RIFD, which are growing in logistics and supply chain in sample organisations. However, there is a lack of scalability, and experts believe the utilisation of IoT is still low.

Major technical challenges include privacy, network, integration among the technologies, access control, authentication, and mobile security. Whereas return on investment, too few best practices, cooperation among the departments, employees' resistance to change (Marcon et al., 2019), and lack of strategical approach even hampers the implementation process. Research studies are scant to the best of our knowledge, which provides a roadmap for practitioners on how to overcome such barriers and successfully implement emerging technologies. 


\section{Issues in Information Systems}

Volume 22, Issue 1, pp. 92-113, 2021

To fill the research gap and provide practitioners with guidelines to successfully implement IoT, we developed a roadmap for successfully implementing emerging technologies in different industrial settings. Experts stressed that the success of technology-related projects lies in the combination of strategical and operational level initiatives. A strategic approach is compulsory for the long-term success of emerging technologies in industries. In the industry 4.0 era, the organisation needs to capture opportunities offered by emerging technologies. Interviewees believe organisations reluctant to implement new technologies might lose potential market share, and in the worst-case scenario, their competitors can wipe them out of the competition. In this perspective, the roadmap can guide organisations to successfully implement emerging technologies and reap the benefits such as new value streams, energy efficiency, supply chain efficiency, enhanced user experience, and financial savings to name a few.

Our study also evaluates AI and BC's role in new businesses. We found out AI has a broad spectrum of applications in current businesses, that is predicted to grow exponentially in the future. While, about $\mathrm{BC}$ technologies, despite theoretical potentials, practitioners have little understanding of business cases. Another reason for the low implementation of $\mathrm{BC}$ is that most organisations depicted higher levels of trust in other technologies such as IoT and AI, which potentially roll out utilising BC in their business cases.

\section{Future research recommendations}

Based on findings of the study, we propose future researchers conduct a study on two major aspects of IoT: First is developing a framework to provide better network and connections for IoT, especially in the context of offshore IoT implementation such as marine logistics and offshore wind power plants. Researchers can evaluate the Role of $5 \mathrm{G}$ technology to enhance offshore network communications. Second, our study provides an overview of different organisational related factors that contribute to the success or failure of emerging technological projects. We suggest future researchers explore what motivates employees and what kind of leadership skills are required to prepare organisations for a higher level of technology adoption. Finally, it is highly recommended to conduct studies to determine business values and use cases for BC technologies. Studies have shown the potential to tackle trust-related issues in ICT technologies; however, studies are rare, providing blockchain-based business models and value streams.

\section{References}

Abdel-Basset, M., Manogaran, G., \& Mohamed, M. (2018). Internet of Things (IoT) and its impact on supply chain: A framework for building smart, secure and efficient systems. Future Generation Computer Systems, 86, 614-628. https://doi.org/10.1016/j.future.2018.04.051

Alabdulsalam, S., Schaefer, K., Kechadi, T., \& Le-Khac, N.-A. (2018). Internet of Things Forensics Challenges and a Case Study. In G. Peterson \& S. Shenoi (Eds.), Advances in Digital Forensics $X I V$ (pp. 35-48). Springer International Publishing. https://doi.org/10.1007/978-3-319-99277-8_3

Al-Ali, A. R. (2016). Internet of Things Role in the Renewable Energy Resources. Energy Procedia, 100, 34-38. https://doi.org/10.1016/j.egypro.2016.10.144

AlEnezi, A., AlMeraj, Z., \& Manuel, P. (2018). Challenges of IoT based Smart-government Development. 2018 21st Saudi Computer Society National Computer Conference (NCC), 1-6. https://doi.org/10.1109/NCG.2018.8593168 


\section{Issues in Information Systems}

Volume 22, Issue 1, pp. 92-113, 2021

Al-Fuqaha, A., Guizani, M., Mohammadi, M., Aledhari, M., \& Ayyash, M. (2015). Internet of Things: A Survey on Enabling Technologies, Protocols, and Applications. IEEE Communications Surveys Tutorials, 17(4), 2347-2376. https://doi.org/10.1109/COMST.2015.2444095

Al-Turjman, F., \& Abujubbeh, M. (2019). IoT-enabled smart grid via SM: An overview. Future Generation Computer Systems, 96, 579-590. https://doi.org/10.1016/j.future.2019.02.012

Arshad, R., Zahoor, S., Shah, M. A., Wahid, A., \& Yu, H. (2017). Green IoT: An Investigation on Energy Saving Practices for 2020 and Beyond. IEEE Access, 5, 15667-15681. https://doi.org/10.1109/ACCESS.2017.2686092

Bandyopadhyay, D., \& Sen, J. (2011). Internet of Things: Applications and Challenges in Technology and Standardization. Wireless Personal Communications: An International Journal, 58(1), 4969. https://doi.org/10.1007/s11277-011-0288-5

Bhattacharyya, S. C. (2011). Energy Economics: Concepts, Issues, Markets and Governance. SpringerVerlag. https://doi.org/10.1007/978-0-85729-268-1

Brous, P., Janssen, M., \& Herder, P. (2019). Internet of Things adoption for reconfiguring decisionmaking processes in asset management. Business Process Management Journal, 25(3), 495-511. https://doi.org/10.1108/BPMJ-11-2017-0328

Cai, H., Xu, L. D., Xu, B., Xie, C., Qin, S., \& Jiang, L. (2014). IoT-Based Configurable Information Service Platform for Product Lifecycle Management. IEEE Transactions on Industrial Informatics, 10(2), 1558-1567. https://doi.org/10.1109/TII.2014.2306391

Chen, S., Xu, H., Liu, D., Hu, B., \& Wang, H. (2014). A Vision of IoT: Applications, Challenges, and Opportunities With China Perspective. IEEE Internet of Things Journal, 1(4), 349-359. https://doi.org/10.1109/JIOT.2014.2337336

Čolaković, A., \& Hadžialić, M. (2018). Internet of Things (IoT): A review of enabling technologies, challenges, and open research issues. Computer Networks, 144, 17-39. https://doi.org/10.1016/j.comnet.2018.07.017

Das, M. L. (2015). Privacy and Security Challenges in Internet of Things. In R. Natarajan, G. Barua, \& M. R. Patra (Eds.), Distributed Computing and Internet Technology (pp. 33-48). Springer International Publishing. https://doi.org/10.1007/978-3-319-14977-6_3

Dyer, C. H., Hammond, G. P., Jones, C. I., \& McKenna, R. C. (2008). Enabling technologies for industrial energy demand management. Energy Policy, 36(12), 4434-4443. https://doi.org/10.1016/j.enpol.2008.09.028 


\section{Issues in Information Systems}

Volume 22, Issue 1, pp. 92-113, 2021

Ejaz, W., Naeem, M., Shahid, A., Anpalagan, A., \& Jo, M. (2017). Efficient Energy Management for the Internet of Things in Smart Cities. IEEE Communications Magazine, 55(1), 84-91. https://doi.org/10.1109/MCOM.2017.1600218CM

Farhan, L., Shukur, S. T., Alissa, A. E., Alrweg, M., Raza, U., \& Kharel, R. (2017). A survey on the challenges and opportunities of the Internet of Things (IoT). 2017 Eleventh International Conference on Sensing Technology (ICST), 1-5. https://doi.org/10.1109/ICSensT.2017.8304465

Final Consumption of Energy-Motiva. (n.d.). Retrieved 30 December 2020, from https://www.motiva.fi/en/solutions/energy_use_in_finland/final_consumption_of_energy

Georgakopoulos, D., Jayaraman, P. P., Fazia, M., Villari, M., \& Ranjan, R. (2016). Internet of Things and Edge Cloud Computing Roadmap for Manufacturing. IEEE Cloud Computing, 3(4), 66-73. https://doi.org/10.1109/MCC.2016.91

Ghorbani, H. R., \& Ahmadzadegan, M. H. (2017). Security challenges in internet of things: Survey. 2017 IEEE Conference on Wireless Sensors (ICWiSe), 1-6. https://doi.org/10.1109/ICWISE.2017.8267153

Gigli, M., \& Koo, S. (2011). Internet of Things: Services and Applications Categorization. Advances in Internet of Things, 1(2), 27-31. https://doi.org/10.4236/ait.2011.12004

Gill, P., Stewart, K., Treasure, E., \& Chadwick, B. (2008). Methods of data collection in qualitative research: Interviews and focus groups. British Dental Journal, 204(6), 291-295. https://doi.org/10.1038/bdj.2008.192

Gnoni, M. G., Bragatto, P. A., Milazzo, M. F., \& Setola, R. (2020). Integrating IoT technologies for an "intelligent" safety management in the process industry. Procedia Manufacturing, 42, 511-515. https://doi.org/10.1016/j.promfg.2020.02.040

Golovatchev, J., Chatterjee, P., Kraus, F., \& Schüssl, R. (2016). The Impact of the IoT on Product Development and Management. ISPIM Innovation Symposium, 1-20. https://search.proquest.com/docview/1803692201/abstract/6A0951637EF54882PQ/1

Hameed, S., Khan, F. I., \& Hameed, B. (2019, January 10). Understanding Security Requirements and Challenges in Internet of Things (IoT): A Review [Review Article]. Journal of Computer Networks and Communications; Hindawi. https://doi.org/10.1155/2019/9629381

Haseeb, K., Almogren, A., Islam, N., Ud Din, I., \& Jan, Z. (2019). An Energy-Efficient and Secure Routing Protocol for Intrusion Avoidance in IoT-Based WSN. Energies, 12(21), 4174. https://doi.org/10.3390/en12214174 


\section{Issues in Information Systems}

Volume 22, Issue 1, pp. 92-113, 2021

Hopkins, J., \& Hawking, P. (2018). Big Data Analytics and IoT in logistics: A case study. The International Journal of Logistics Management, 29(2), 575-591. https://doi.org/10.1108/IJLM05-2017-0109

Hossain, M. S., Madlool, N. A., Rahim, N. A., Selvaraj, J., Pandey, A. K., \& Khan, A. F. (2016). Role of smart grid in renewable energy: An overview. Renewable and Sustainable Energy Reviews, 60, 1168-1184. https://doi.org/10.1016/j.rser.2015.09.098

Hossein Motlagh, N., Mohammadrezaei, M., Hunt, J., \& Zakeri, B. (2020). Internet of Things (IoT) and the Energy Sector. Energies, 13(2), 494. https://doi.org/10.3390/en13020494

Hoyer, W. D., Kroschke, M., Schmitt, B., Kraume, K., \& Shankar, V. (2020). Transforming the Customer Experience Through New Technologies. Journal of Interactive Marketing, 51, 57-71. https://doi.org/10.1016/j.intmar.2020.04.001

Hozdić, E. (n.d.). SMART FACTORY FOR INDUSTRY 4.0: A REVIEW. 8.

Hsu, C.-L., \& Lin, J. C.-C. (2016). An empirical examination of consumer adoption of Internet of Things services: Network externalities and concern for information privacy perspectives. Computers in Human Behavior, 62, 516-527. https://doi.org/10.1016/j.chb.2016.04.023

Hsu, C.-L., \& Lin, J. C.-C. (2018). Exploring Factors Affecting the Adoption of Internet of Things Services. Journal of Computer Information Systems, 58(1), 49-57. https://doi.org/10.1080/08874417.2016.1186524

Ingemarsdotter, E., Jamsin, E., \& Balkenende, R. (2020). Opportunities and challenges in IoT-enabled circular business model implementation - A case study. Resources, Conservation and Recycling, 162, 105047. https://doi.org/10.1016/j.resconrec.2020.105047

Jing, Q., Vasilakos, A. V., Wan, J., Lu, J., \& Qiu, D. (2014). Security of the Internet of Things: Perspectives and challenges. Wireless Networks, 20(8), 2481-2501. https://doi.org/10.1007/s11276-014-0761-7

Kecskemeti, G., Casale, G., Jha, D. N., Lyon, J., \& Ranjan, R. (2017). Modelling and Simulation Challenges in Internet of Things. IEEE Cloud Computing, 4(1), 62-69. https://doi.org/10.1109/MCC.2017.18

Khan, W. Z., Rehman, M. H., Zangoti, H. M., Afzal, M. K., Armi, N., \& Salah, K. (2020). Industrial internet of things: Recent advances, enabling technologies and open challenges. Computers \& Electrical Engineering, 81, 106522. https://doi.org/10.1016/j.compeleceng.2019.106522

Khanda, K., Salikhov, D., Gusmanov, K., Mazzara, M., \& Mavridis, N. (2017). Microservice-Based IoT for Smart Buildings. 2017 31st International Conference on Advanced Information Networking and Applications Workshops (WAINA), 302-308. https://doi.org/10.1109/WAINA.2017.77 


\section{Issues in Information Systems}

Volume 22, Issue 1, pp. 92-113, 2021

Koohang, A., Nowak, A., Paliszkiewicz, J., \& Nord, J. H. (2020). Information Security Policy Compliance: Leadership, Trust, Role Values, and Awareness. Journal of Computer Information Systems, 60(1), 1-8. https://doi.org/10.1080/08874417.2019.1668738

Kumar, N. M., \& Mallick, P. K. (2018). Blockchain technology for security issues and challenges in IoT. Procedia Computer Science, 132, 1815-1823. https://doi.org/10.1016/j.procs.2018.05.140

Kummitha, R. K. R., \& Crutzen, N. (2019). Smart cities and the citizen-driven internet of things: A qualitative inquiry into an emerging smart city. Technological Forecasting and Social Change, 140, 44-53. https://doi.org/10.1016/j.techfore.2018.12.001

Lasi, H., Fettke, P., Kemper, H.-G., Feld, T., \& Hoffmann, M. (2014). Industry 4.0. Business \& Information Systems Engineering, 6(4), 239-242. https://doi.org/10.1007/s12599-014-0334-4

Lee, I., \& Lee, K. (2015). The Internet of Things (IoT): Applications, investments, and challenges for enterprises. Business Horizons, 58(4), 431-440. https://doi.org/10.1016/j.bushor.2015.03.008

Lennvall, T., Gidlund, M., \& Åkerberg, J. (2017). Challenges when bringing IoT into industrial automation. 2017 IEEE AFRICON, 905-910. https://doi.org/10.1109/AFRCON.2017.8095602

Lim, M. K., Bahr, W., \& Leung, S. C. H. (2013). RFID in the warehouse: A literature analysis (19952010) of its applications, benefits, challenges and future trends. International Journal of Production Economics, 145(1), 409-430. https://doi.org/10.1016/j.ijpe.2013.05.006

Lin, F., Chen, C., Zhang, N., Guan, X., \& Shen, X. (2016). Autonomous Channel Switching: Towards Efficient Spectrum Sharing for Industrial Wireless Sensor Networks. IEEE Internet of Things Journal, 3(2), 231-243. https://doi.org/10.1109/JIOT.2015.2490544

Lu, Y. (2017). Industry 4.0: A survey on technologies, applications and open research issues. Journal of Industrial Information Integration, 6, 1-10. https://doi.org/10.1016/j.jii.2017.04.005

Lund, D., MacGillivray, C., Turner, V., \& Morales, M. (2014). Worldwide and regional internet of things (iot) 2014-2020 forecast: A virtuous circle of proven value and demand. International Data Corporation (IDC), Tech. Rep, 1, 9.

Maple, C. (2017). Security and privacy in the internet of things. Journal of Cyber Policy, 2(2), 155-184. https://doi.org/10.1080/23738871.2017.1366536

Marcon, É., Marcon, A., Le Dain, M.-A., Ayala, N. F., Frank, A. G., \& Matthieu, J. (2019). Barriers for the digitalization of servitization. Procedia CIRP, 83, 254-259. https://doi.org/10.1016/j.procir.2019.03.129 


\section{Issues in Information Systems}

Volume 22, Issue 1, pp. 92-113, 2021

Mourtzis, D., Vlachou, E., \& Milas, N. (2016). Industrial Big Data as a Result of IoT Adoption in Manufacturing. Procedia CIRP, 55, 290-295. https://doi.org/10.1016/j.procir.2016.07.038

Mrabet, H., Belguith, S., Alhomoud, A., \& Jemai, A. (2020). A Survey of IoT Security Based on a Layered Architecture of Sensing and Data Analysis. Sensors, 20(13), 3625. https://doi.org/10.3390/s20133625

Nguyen, B., \& Simkin, L. (2017). The Internet of Things (IoT) and marketing: The state of play, future trends and the implications for marketing. Journal of Marketing Management, 33(1-2), 1-6. https://doi.org/10.1080/0267257X.2016.1257542

Nižetić, S., Šolić, P., López-de-Ipiña González-de-Artaza, D., \& Patrono, L. (2020). Internet of Things (IoT): Opportunities, issues and challenges towards a smart and sustainable future. Journal of Cleaner Production, 274, 122877. https://doi.org/10.1016/j.jclepro.2020.122877

Nord, J. H., Koohang, A., \& Paliszkiewicz, J. (2019). The Internet of Things: Review and theoretical framework. Expert Systems with Applications, 133, 97-108. https://doi.org/10.1016/j.eswa.2019.05.014

Ouaddah, A., Mousannif, H., Abou Elkalam, A., \& Ait Ouahman, A. (2017). Access control in the Internet of Things: Big challenges and new opportunities. Computer Networks, 112, 237-262. https://doi.org/10.1016/j.comnet.2016.11.007

Paiola, M., \& Gebauer, H. (2020). Internet of things technologies, digital servitization and business model innovation in BtoB manufacturing firms. Industrial Marketing Management, 89, 245-264. https://doi.org/10.1016/j.indmarman.2020.03.009

Paliszkiewicz, J. (2019). Information Security Policy Compliance: Leadership and Trust. Journal of Computer Information Systems, 59(3), 211-217. https://doi.org/10.1080/08874417.2019.1571459

Pathak, V., Jena, B., \& Kalra, S. (2013). Qualitative research. Perspectives in Clinical Research, 4(3), 192. https://doi.org/10.4103/2229-3485.115389

Pfeiffer, S. (2016). Robots, Industry 4.0 and Humans, or Why Assembly Work Is More than Routine Work. Societies, 6(2), 16. https://doi.org/10.3390/soc6020016

Pflaum, A. A., \& Golzer, P. (2018). The IoT and Digital Transformation: Toward the Data-Driven Enterprise. IEEE Pervasive Computing, 17(1), 87-91. https://doi.org/10.1109/MPRV.2018.011591066

Porter, M. E., \& Heppelmann, J. E. (2014). How smart, connected products are transforming competition. Harvard Business Review, 92(11), 64-88. 


\section{Issues in Information Systems}

Volume 22, Issue 1, pp. 92-113, 2021

Ramamurthy, A., \& Jain, P. (2017). The Internet of Things in the Power Sector: Opportunities in Asia and the Pacific (Issue 48). Asian Development Bank. https://www.adb.org/publications/internetof-things-power-sector-opportunities

Roblek, V., Meško, M., \& Krapež, A. (2016). A Complex View of Industry 4.0. SAGE Open, 6(2), 2158244016653987. https://doi.org/10.1177/2158244016653987

Schmitt, G., Mladenow, A., Strauss, C., \& Schaffhauser-Linzatti, M. (2019). Smart Contracts and Internet of Things: A Qualitative Content Analysis using the Technology-Organization-Environment Framework to Identify Key-Determinants. Procedia Computer Science, 160, 189-196. https://doi.org/10.1016/j.procs.2019.09.460

Schwab, K. (2017). The Fourth Industrial Revolution. Crown.

Shaikh, F. K., Zeadally, S., \& Exposito, E. (2017). Enabling Technologies for Green Internet of Things. IEEE Systems Journal, 11(2), 983-994. https://doi.org/10.1109/JSYST.2015.2415194

Shakeel, S. R., Takala, J., \& Zhu, L.-D. (2017). Commercialization of renewable energy technologies: A ladder building approach. Renewable and Sustainable Energy Reviews, 78, 855-867. https://doi.org/10.1016/j.rser.2017.05.005

Smidt, H., Thornton, M., \& Ghorbani, R. (2018, January 3). Smart Application Development for IoT Asset Management Using Graph Database Modeling and High-Availability Web Services. https://doi.org/10.24251/HICSS.2018.725

Sood, K., Yu, S., \& Xiang, Y. (2016). Software-Defined Wireless Networking Opportunities and Challenges for Internet-of-Things: A Review. IEEE Internet of Things Journal, 3(4), 453-463. https://doi.org/10.1109/JIOT.2015.2480421

Stoyanova, M., Nikoloudakis, Y., Panagiotakis, S., Pallis, E., \& Markakis, E. K. (2020). A Survey on the Internet of Things (IoT) Forensics: Challenges, Approaches, and Open Issues. IEEE Communications Surveys Tutorials, 22(2), 1191-1221. https://doi.org/10.1109/COMST.2019.2962586

Tan, Y. S., Ng, Y. T., \& Low, J. S. C. (2017). Internet-of-Things Enabled Real-time Monitoring of Energy Efficiency on Manufacturing Shop Floors. Procedia CIRP, 61, 376-381. https://doi.org/10.1016/j.procir.2016.11.242

Tao, F., Wang, Y., Zuo, Y., Yang, H., \& Zhang, M. (2016). Internet of Things in product life-cycle energy management. Journal of Industrial Information Integration, 1, 26-39. https://doi.org/10.1016/j.jii.2016.03.001 


\section{Issues in Information Systems}

Volume 22, Issue 1, pp. 92-113, 2021

Teoh, Y. K., Gill, S. S., \& Parlikad, A. K. (2021). IoT and Fog Computing based Predictive Maintenance Model for Effective Asset Management in Industry 4.0 using Machine Learning. IEEE Internet of Things Journal, 1-1. https://doi.org/10.1109/JIOT.2021.3050441

Thibaud, M., Chi, H., Zhou, W., \& Piramuthu, S. (2018). Internet of Things (IoT) in high-risk Environment, Health and Safety (EHS) industries: A comprehensive review. Decision Support Systems, 108, 79-95. https://doi.org/10.1016/j.dss.2018.02.005

Virat, M. S., Bindu, S. M., Aishwarya, B., Dhanush, B. N., \& Kounte, M. R. (2018). Security and Privacy Challenges in Internet of Things. 2018 2nd International Conference on Trends in Electronics and Informatics (ICOEI), 454-460. https://doi.org/10.1109/ICOEI.2018.8553919

Wan, J., Chen, B., Imran, M., Tao, F., Li, D., Liu, C., \& Ahmad, S. (2018). Toward Dynamic Resources Management for IoT-Based Manufacturing. IEEE Communications Magazine, 56(2), 52-59. https://doi.org/10.1109/MCOM.2018.1700629

Weber, R. H. (2010). Internet of Things - New security and privacy challenges. Computer Law \& Security Review, 26(1), 23-30. https://doi.org/10.1016/j.clsr.2009.11.008

Wilson, E., Kenny, A., \& Dickson-Swift, V. (2015). Using Blogs as a Qualitative Health Research Tool: A Scoping Review. International Journal of Qualitative Methods, 14(5), 1609406915618049. https://doi.org/10.1177/1609406915618049

Wortmann, F., \& Flüchter, K. (2015). Internet of Things. Business \& Information Systems Engineering, 57(3), 221-224. https://doi.org/10.1007/s12599-015-0383-3

Younan, M., Houssein, E. H., Elhoseny, M., \& Ali, A. A. (2020). Challenges and recommended technologies for the industrial internet of things: A comprehensive review. Measurement, 151, 107198. https://doi.org/10.1016/j.measurement.2019.107198

Zouinkhi, A., Ayadi, H., Val, T., Boussaid, B., \& Abdelkrim, M. N. (2020). Auto-management of energy in IoT networks. International Journal of Communication Systems, 33(1), e4168.

https://doi.org/10.1002/dac.4168 


\section{Appendix A}

\section{Background information of participants}

\begin{tabular}{|c|c|c|c|c|}
\hline Company & Interviewee (Position) & Organisation products/Services & Experience & Country \\
\hline A & $\begin{array}{l}\text { Director of Innovation, Global } \\
\text { product line manager }\end{array}$ & $\begin{array}{l}\text { IoT system configurator, } \\
\text { customised solutions \& } \\
\text { professional services }\end{array}$ & 30 years & Finland \\
\hline B & IoT systems developer & Marine Power, Diesel engines & 5 years & Finland \\
\hline $\mathrm{C}$ & $\begin{array}{l}\mathrm{PhD} \text { Researcher, IoT } \\
\text { architecture specialist }\end{array}$ & $\begin{array}{l}\text { Smart building, smart heating } \\
\text { solutions }\end{array}$ & 3 years & Finland \\
\hline $\mathrm{D}$ & $\begin{array}{l}\text { Master builder, emerging } \\
\text { technologies }\end{array}$ & $\begin{array}{l}\text { IoT solutions for the energy } \\
\text { sector }\end{array}$ & 7 years & Finland \\
\hline $\mathrm{E}$ & $\begin{array}{l}\text { Business Development } \\
\text { Manager }\end{array}$ & Industrial IoT & 3 years & Finland \\
\hline $\mathrm{F}$ & Systems architect & $\begin{array}{l}\text { Cutting tools Tech for the energy } \\
\text { industry }\end{array}$ & 10 years & Finland \\
\hline G & Application Engineer & $\begin{array}{l}\text { Drive technology, variable speed } \\
\text { generator technology, energy } \\
\text { storage system, Dedicated Power } \\
\text { Management System. }\end{array}$ & 5 years & Finland \\
\hline
\end{tabular}




\section{Appendix B}

\section{Major applications and utilisation of IoT}

\begin{tabular}{|c|c|c|}
\hline \multirow[t]{2}{*}{$\begin{array}{l}\text { Manufacturi } \\
\text { ng }\end{array}$} & $\begin{array}{l}\text { We have in our factory thousands of sensors, measure pressure applying and } \\
\text { measuring rolling and lot of other things, these sensors have been mainly } \\
\text { used inside the machine, and we are now live streaming sensors values to the } \\
\text { cloud, storing it to the data lakes and we do visualisation and next step is to } \\
\text { start optimising through data analysis to see what dimensions effect quality } \\
\text { the most. }\end{array}$ & $\begin{array}{l}\text { IoT System } \\
\text { Developer }\end{array}$ \\
\hline & $\begin{array}{l}\text { We did actually created the manufacturing execution system a kind of having } \\
\text { smart connected assets in the field to monitor the performance of all } \\
\text { components in the manufacturing process, especially in the service area } \\
\text { perform preventive maintenance but then also they are using it for fault } \\
\text { Finding. }\end{array}$ & $\begin{array}{l}\text { Business } \\
\text { Developme } \\
\text { nt Manager }\end{array}$ \\
\hline $\begin{array}{l}\text { Smart grid, } \\
\text { energy } \\
\text { systems }\end{array}$ & $\begin{array}{l}\text { We have kind of horizontal solutions for the network is used for power } \\
\text { quality monitoring but then also so for example like } \mathrm{H}^{* * * *} \text { use that for solar } \\
\text { factories for connecting different types of assets to realise demand response } \\
\text { elasticity scenario, stabilise the grid frequency of } 50 \text { hertz automatically to } \\
\text { all the big power plants..... [....] hydropower plants are controlled from that } \\
\text { energy storage solution. }\end{array}$ & $\begin{array}{l}\text { Director } \\
\text { Innovation }\end{array}$ \\
\hline \multirow[t]{2}{*}{$\begin{array}{l}\text { Information } \\
\text { Technology }\end{array}$} & $\begin{array}{l}\text { Our organisation provides digital solutions and professional services in the } \\
\text { domain of IoT and AI, and we use IT in combination with our customised } \\
\text { solutions to provide sustainable digital solutions to our partner companies. }\end{array}$ & $\begin{array}{l}\text { Master } \\
\text { Builder } \\
\text { Emerging } \\
\text { Technologi } \\
\text { es }\end{array}$ \\
\hline & $\begin{array}{l}\text { Obviously, the aim of our IT is to provide information in decision making, } \\
\text { and implementing IoT enabled us to collect data, the large amount of data } \\
\text { and now we see in our manufacturing and product development it is helping } \\
\text { a lot by reporting discrepancies and enabling process automation. So, the } \\
\text { combination of IT and IoT is working well for us. }\end{array}$ & $\begin{array}{l}\text { System } \\
\text { Architect }\end{array}$ \\
\hline \multirow[t]{2}{*}{$\begin{array}{l}\text { Logistics \& } \\
\text { Marine } \\
\text { powers }\end{array}$} & $\begin{array}{l}\text { We have ***** (organisation name) self-built marine engines and we have } \\
\text { IoT devices in the field which actually collect data from engines and then } \\
\text { publish data to the cloud where we have MQTT brokers and collect the data } \\
\text { and then finally data is consumed by analytics downstream customer to } \\
\text { provide valuable user experience to the end customer. }\end{array}$ & $\begin{array}{l}\text { IoT systems } \\
\text { Developer }\end{array}$ \\
\hline & $\begin{array}{l}\text { Our organisation uses IoT in multiple projects related to smart grid and } \\
\text { Marine power solutions. However, we have just started implementing IoT } \\
\text { related projects and utilisation is at its basic level. }\end{array}$ & $\begin{array}{l}\text { Application } \\
\text { Engineer }\end{array}$ \\
\hline $\begin{array}{l}\text { Energy } \\
\text { efficiency }\end{array}$ & $\begin{array}{l}\text { We have a start-up company of which we have developed some products with } \\
\text { the help of IoT.... like Building an automation system for heating and cooling } \\
\text { off of any house...., it can detect if the people are at home or if the people } \\
\text { are outside and turning the heating on/off, ultimately cutting the heating } \\
\text { energy by } 40 \% \text {, and it's a huge contribution in energy efficiency. }\end{array}$ & $\begin{array}{l}\text { IoT } \\
\text { Architect } \\
\text { Specialist }\end{array}$ \\
\hline
\end{tabular}




\section{Appendix C}

Sample discussion on major challenges and benefits

\begin{tabular}{|c|c|c|}
\hline \multirow[t]{3}{*}{$\begin{array}{l}\text { Technical } \\
\text { challenges }\end{array}$} & $\begin{array}{l}\text { I think for our organisation network is the most challenging } \\
\text { especially if we talk about sites and fields where Marine operates, } \\
\ldots[\ldots] \ldots \text { changing their IP'S and it makes quite challenging. }\end{array}$ & $\begin{array}{l}\text { IoT Systems } \\
\text { Developer }\end{array}$ \\
\hline & $\begin{array}{l}\text { We have kind of edge device which is batching and buffering data } \\
\text { and if the Internet connectivity will go down, so we have to buffer } \\
\text { the data, so the connection restored,... [...] ... MQQT protocols } \\
\text { authenticate and how we orchestrate and manage from an } \\
\text { operational perspective, these are kind of challenges we have } \\
\text { looked at that. }\end{array}$ & $\begin{array}{l}\text { Systems } \\
\text { Architect }\end{array}$ \\
\hline & $\begin{array}{l}\text { Challenge of interoperability, in our technologies we are utilising } \\
\text { a proprietary connectivity platform.... it is ideal for our } \\
\text { applications for our devices essential ... [...] ... we have } \\
\text { developed our whole product around that connectivity protocol, } \\
\text { one of the biggest problems is with industrial customers clients } s \\
\text { they have very closed systems. }\end{array}$ & $\begin{array}{l}\text { Business } \\
\text { Development } \\
\text { Manage }\end{array}$ \\
\hline \multirow[t]{3}{*}{$\begin{array}{l}\text { Organisational } \\
\text { level barriers }\end{array}$} & $\begin{array}{l}\text { Major challenge was organisation going though transformational } \\
\text { phase ...[... } . . . \text {, taking on board and coordination among all } \\
\text { stakeholders was big challenge ... [...] ... transformation is always } \\
\text { painful and human nature tend to resist to come out of comfort } \\
\text { zone, and it was driven well by the management, by having more } \\
\text { and more information sessions and discussing why transformation } \\
\text { is necessary. }\end{array}$ & $\begin{array}{l}\text { IoT Systems } \\
\text { Developer. }\end{array}$ \\
\hline & $\begin{array}{l}\text { I think it's always about people about decision-makers people are } \\
\text { always an issue and when it comes down to implementing new } \\
\text { technologies because of course it's much easier to try to mitigate } \\
\text { the risk rather than trying to catch opportunities...[...]... it's much } \\
\text { more challenging for them to start implementing new technology } \\
\text { which might not bring return-on-investment immediately but will } \\
\text { bring in the next } 2 \text { to } 3 \text { years or this might not apply to everyone } \\
\text { but especially for talking about decision-makers. }\end{array}$ & $\begin{array}{l}\text { Business } \\
\text { Development } \\
\text { Manager }\end{array}$ \\
\hline & $\begin{array}{l}\text { People might feel threaten in an organisation actually by an IoT in } \\
\text { some degree kind of start boycotting the external solutions, spread } \\
\text { misinformation starts working against it ... [...] ... it becomes real } \\
\text { distractor that is very hazardous. }\end{array}$ & $\begin{array}{l}\text { Director of } \\
\text { Innovation }\end{array}$ \\
\hline $\begin{array}{l}\text { Return on } \\
\text { investment }\end{array}$ & $\begin{array}{l}\text { Matter on return-on-investment is very tricky because from my } \\
\text { personal experience the way how it is being calculated in our } \\
\text { industry is tricky, a lot of IoT related projects around } 70-80 \% \text { fails } \\
\text { in their POC stage and in my experience, it happens because the } \\
\text { objectives of the POC are not clearly pretty define.......... it's } \\
\text { much more challenging for them to start implementing new } \\
\text { technology which might not bring return-on-investment } \\
\text { immediately. }\end{array}$ & $\begin{array}{l}\text { Business } \\
\text { Development } \\
\text { Manager }\end{array}$ \\
\hline
\end{tabular}




\section{Issues in Information Systems}

Volume 22, Issue 1, pp. 92-113, 2021

\begin{tabular}{|l|l|l|}
\hline & $\begin{array}{l}\text { About return on investment the project is still in initial phases and } \\
\text { gradual changes are happening, implementing IoT requires high } \\
\text { investments, it is a challenge indeed. }\end{array}$ & $\begin{array}{l}\text { IoT Systems } \\
\text { Developer }\end{array}$ \\
\hline \multicolumn{3}{|c|}{ Benefits } \\
\hline $\begin{array}{l}\text { New revenue } \\
\text { streams, financial } \\
\text { savings, Health \& } \\
\text { safety }\end{array}$ & $\begin{array}{l}\text { In my opinion is always comes down to these three points, of } \\
\text { course, you have a lot of subcategories to you everything but the } \\
\text { main things more about new revenue streams and health and } \\
\text { safety, cutting cost. }\end{array}$ & $\begin{array}{l}\text { Director of } \\
\text { Innovation }\end{array}$ \\
\hline $\begin{array}{l}\text { New business } \\
\text { streams, supply } \\
\text { chain efficiency }\end{array}$ & $\begin{array}{l}\text { For our organisation its new business opportunity, making } \\
\text { company more efficient and enhancing supply chain efficiency by } \\
\text { real time monitoring of logistic and information transparency. }\end{array}$ & $\begin{array}{l}\text { Builder } \\
\text { Emerging } \\
\text { Technologies }\end{array}$ \\
\hline $\begin{array}{l}\text { Energy efficiency, } \\
\text { enhanced user } \\
\text { experience, } \\
\text { customer services }\end{array}$ & $\begin{array}{l}\text { Yes, implementing IoT has been beneficial in terms of energy } \\
\text { efficiency, enhancing user experience, customer services by } \\
\text { providing real time data on engines energy consumptions, but the } \\
\text { matter of fact about return on investment and financial benefits, } \\
\text { the project is in initial phases and we have not realised financial } \\
\text { benefits. }\end{array}$ & $\begin{array}{l}\text { IoT Systems } \\
\text { Developer }\end{array}$ \\
\hline
\end{tabular}

